\title{
Study of children of parents operated on for congenital cardiovascular malformations
}

\author{
ANDREW CZEIZEL, ANN PORNOI, ELISABETH PETERFFY, EVE TARCAL \\ From the Department of Human Genetics, National Institute of Hygiene, and the Department of Pediatrics, National \\ Institute of Cardiology, Budapest, Hungary
}

SUMMARY The incidence of congenital cardiovascular malformation was studied in 246 children of $\sim \overrightarrow{+}$ 166 index patients who had been operated upon for this. Twelve children were affected (4.9\%). $\dot{\omega}$ More than half of these had the same malformation as the parent. The incidence of other extracar- $\&$ diac congenital abnormalities did not exceed that recorded in Hungary for the population in general.

The aetiology of the more common types of congenital cardiovascular malformation, for example ventricular septal defect, can best be explained on the basis of the multifactorial threshold model. ${ }^{1}$ In Hungary, the risk of a congenital cardiovascular malformation occurring in the sibs of an affected patient was found to be about $3 \%$ for ventricular septal defect ${ }^{2}$ and for secundum atrial septal defect. ${ }^{3}$ These figures are in accord with previously published data. ${ }^{4}$ Information on the risk in the children of such patients, however, is scanty, probably because of the previously low survival rate of patients with these congenital abnormalities. Because of significant advances in cardiovascular surgery in the past 25 years, the situation has changed. At present, the majority of patients with congenital cardiovascular malformations survive, with a good chance of having children, and it is therefore important to establish the risk of these having similar lesions. In early studies, Neill and Swanson ${ }^{5}$ found the incidence to be $4.8 \%$ of the children of affected mothers and Nora et al. ${ }^{167} 2.6$ to $4.3 \%$ of the children of both affected men and women. Zetterquist, ${ }^{8}$ Ando et al. $^{9}$ and, more recently, Dennis and Warren ${ }^{10}$ have also provided data indicating a risk of approximately $3 \%$. We report a follow up survey of the children of index patients who had undergone surgery for a congenital cardiovascular malformation.

\section{Subjects and methods}

In 1977, the names, birth dates, addresses, clinical diagnoses, and blood groups of all patients born in or before the year 1950 who had undergone surgery for a congenital cardiovascular malformation were obtained

Accepted for publication 14 July 1981 from the files of the National Institute of Cardiology, $\frac{\vec{D}}{\widehat{c}}$ Budapest. Patients who had both cardiovascular and extracardiac abnormalities, that is identifiable or non- $\vec{\oplus}$ identifiable syndromes, were excluded from the? study. Our sample consisted of 539 index patients, 210 men and 329 women. The number and sex distribution for each type of malformation are shown in Table 1. A brief questionnaire concerning family status, number and outcome of pregnancies, as well as $\frac{\Phi}{\varnothing}$ the health of children if any, with special reference to $\stackrel{\Rightarrow}{\Rightarrow}$ the occurrence of cardiovascular malformations was sent to every patient. The Figure summarises the results of the survey. Sixty-five per cent of the patients responded. The relatively high proportion "not located" can be explained by the high social $\mathbb{ه}$ mobility in Hungary and by the fact that many of the patients were now independent adults and had already left home. The actual percentage of changed addresses was even higher than $20 \%$, but we were able too find some patients with the help of the municipal council organisations. There is no reason to believes that the proportion of children found to be affected by congenital cardiovascular malformations would have? been much different if we had been able to find theN missing index patients. The $15 \%$ "no response" category is a better figure than usual and suggests that the patients were co-operative. In all, data werew obtained on $85 \%$ of the cases we were able to find.

All children thought by their parents to have a con $\frac{0}{C}$ genital cardiovascular malformation were called to the National Institute of Cardiology for examination? Those reported as "not-affected" were referred to the regional paediatric outpatient clinic. The necropsy on the six children who had died did not indicate the? occurrence of heart defects in any cases. 
Table 1 Type of congenital cardiovascular malformations of index patients and their children

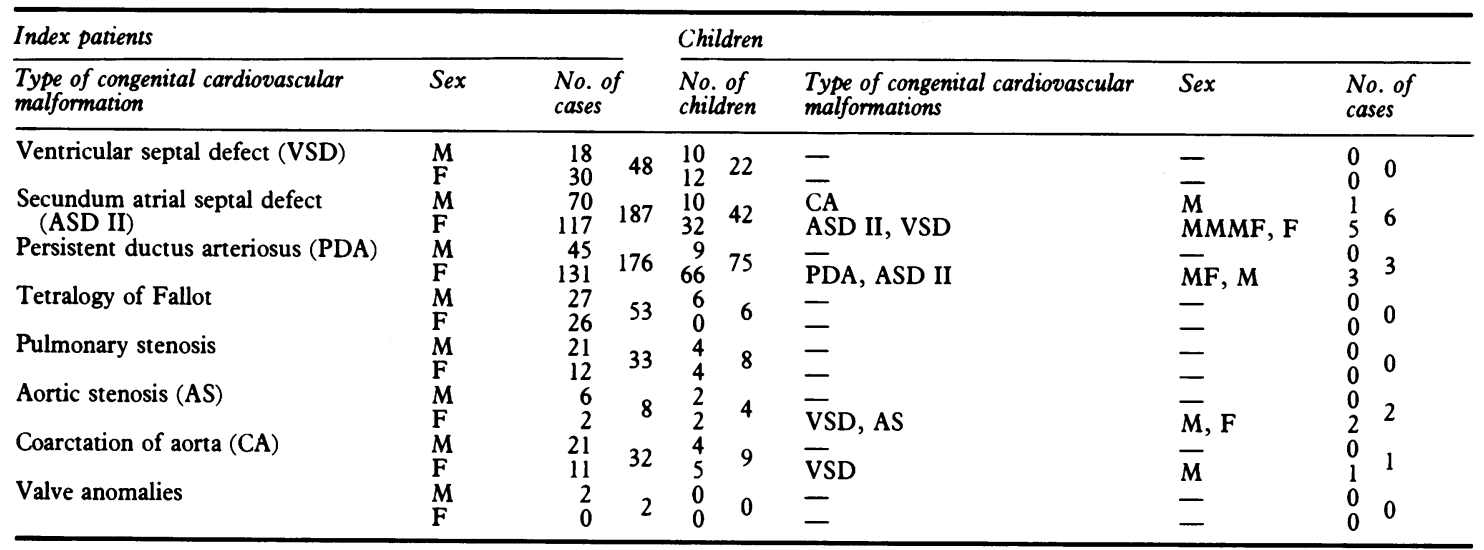

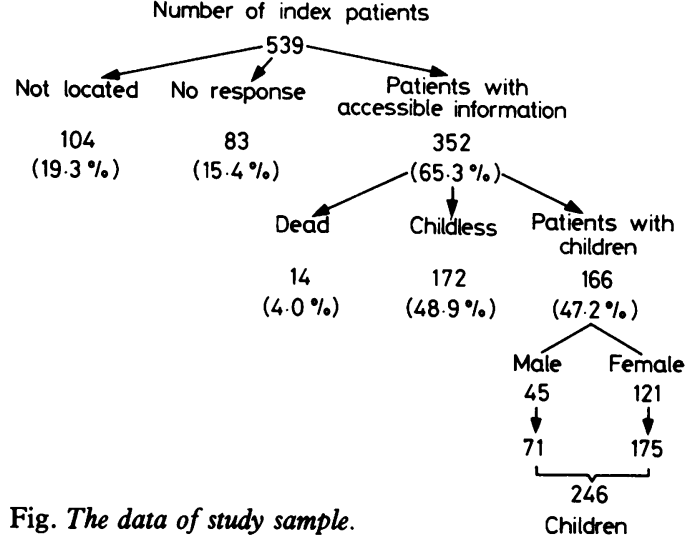

\section{Results}

Fourteen of the 352 index patients about whom there was information had died (Fig) and 172 did not have children (101 of them were unmarried). In all, 166 married patients had had a total of 246 children, an average of 1.48 children per patient. The patients also reported 50 unsuccessful pregnancies (Table 2). The national figures of spontaneous abortions (1.3\%), ectopic pregnancies $(0 \cdot 2 \%)$, and stillbirths $(0.8 \%)$ are not significantly different from those which had occurred. The percentage of female patients who had had a spontaneous abortion was, however, significantly higher that that in the wives of male patients $\left(\chi_{1}^{2}=6.49\right.$; $p<0.05$ ), suggesting an effect of congenital cardiovascular malformation on the pregnancy itself. Nevertheless, it must be noted that men may not be a reliable source of information on this particular question.

Out of the total of 246 children in the study, 16 were thought to have a congenital cardiovascular malformation, an apparent incidence of $6.5 \%$ of live births. One hundred and fifty-one index patients had 222 healthy children, six had one affected child only, one had two affected children, and eight had one affected and one unaffected child. Fifteen of the allegedly affected 16 children underwent cardiological examination at the National Institute of Cardiology. Only seven of them were found to have a congenital cardiovascular malformation, while the remaining eight had functional or innocent murmurs without an underlying organic disorder. The child who was not brought to the institute for examination turned out to have a heart defect, previously adequately documented, and was thus considered to be "affected".

Thus, information obtained from the patients con-

Table 2 Outcome of index patients' pregnancies

\begin{tabular}{|c|c|c|c|c|c|c|}
\hline \multirow{2}{*}{$\begin{array}{l}\text { Index patients } \\
\text { Outcome } \\
\text { of pregnancy }\end{array}$} & \multicolumn{2}{|c|}{ Male $N=45$} & \multicolumn{2}{|c|}{ Female $N=121$} & \multicolumn{2}{|c|}{ Total $N=166$} \\
\hline & $\boldsymbol{M}$ & Rate & $M$ & Rate & $M$ & Rate \\
\hline $\begin{array}{l}\text { Spontaneous abortion } \\
\text { Ectopic pregnancy } \\
\text { Stillbirth } \\
\text { Livebirth } \\
\text { Total }\end{array}$ & $\begin{array}{l}5 \\
1 \\
71 \\
77\end{array}$ & $\begin{array}{l}6.5 \% \star \\
0.0 \% \%^{\star} \\
1.3 \% \star \star \\
1.6+ \\
1.7 \dagger\end{array}$ & $\begin{array}{r}41 \\
1 \\
2 \\
175 \\
219\end{array}$ & $\begin{array}{l}18.7 \%^{\star} \\
0.0 \% \%^{\star} \\
1 \cdot 1 \%^{\star \star} \\
1.4 t \\
1.8 t\end{array}$ & $\begin{array}{r}46 \\
1 \\
3 \\
246 \\
296\end{array}$ & $\begin{array}{l}15.5 \% \%^{\star} \\
0.3 \% \%^{\star} \\
1.2 \% \%^{\star \star} \\
1.5 t \\
1.8 \dagger\end{array}$ \\
\hline
\end{tabular}

* Occurrence per 100 total planned pregnancies.

$\star \star$ Occurrence per 100 total births.

†Livebirths or total planned pregnancies per one index patient. 
cerning their children proved to be only $50 \%$ reliable and the true incidence of congenital cardiovascular malformation in those children appeared to be $3.25 \%$.

Only $66.5 \%$ of the 230 children referred to the outpatient paediatric clinics attended for examination. This ratio is far from satisfactory. We did, however, receive information from several, but not all, of the patients concerned that their child had already been examined for cardiovascular abnormalities, and had been found to be healthy. Four of the children actually examined at the clinics were found to have a congenital cardiovascular malformation; three had a secundum atrial septal defect, and one a coarctation of the aorta. Thus, in the case of children considered to be "not-affected" parental information was $97 \%$ correct (143 of 153). Adding the above four cases to the number of affected children increased the incidence of congenital cardiovascular malformation in the children to $4.9 \%$.

\section{Discussion}

The incidence of congenital cardiovascular abnormality of $4.9 \%$ is five times higher than that found at birth in the newborn in Hungary, 1112 and about 1.6 times higher than that found in sibs. ${ }^{23}$ This figure, furthermore, should be regarded as a minimal value since there might have been further affected children among the remaining 77 who did not attend the outpatient clinics.

Four additional points merit discussion. One of these is the similarity in many cases of the lesion in the parents and their children. The same type of malformation was observed in both parent and child in seven out of 12 cases. This clearly suggests a specific genetic factor though the remaining five children had a different malformation from their parents indicating that congenital cardiovascular malformations are not as type-specific as other congenital abnormalities.

A second point concerns the relative incidence of the different types of congenital cardiovascular malformations in the children. Our sample is not large enough to allow firm conclusions in this respect but it is worthy of note that both of the women with aortic stenosis had an affected child, one of them having aortic stenosis, and that when one parent had a secundum atrial septal defect the apparent risk of a child having a cardiac lesion was over $14 \%$ ( 6 out of 42 ). Four of these six children had the same type of defect as the parent. The mode of inheritance of atrial septal defect and atrial septal defect with atrioventricular conduction defects has been described as being by an autosomal dominant phenotype, and this particular mode of inheritance is considered definite in McKusick' ${ }^{13}$ catalogue. If all or some of these families had secundum atrial septal defect type of autosomal dominant origin this could make the recurrence risk we found seem too high.

The third important problem is whether a distinction can be made between the genetic and the environmental factors (teratogen, maternal) in the development of congenital cardiovascular malformations. Analysis of the sex of the affected parents might be instructive. We found, unexpectedly, that in 11 of the 12 affected children it was the mother who was the original patient. In other words, among the 175 children of the 121 affected women the incidence of malformation was $6.3 \%$, whereas among the 71 children of the 45 affected men it was only $1.4 \%$. This difference, however, is not statistically significant $(p=0 \cdot 10)$. The common types of congenital cardiovascular malformation are the most likely to correspond to the multifactorial threshold model. ${ }^{14}$ The relatively low total recurrence rate may reflect the polygenic liability. The seemingly higher prevalence among the children of affected mothers may be the result of possible triggering effects of environmental (intrauterine) maternal factors.

Finally the prevalence of other congenital abnormalities $(3 \cdot 25 \%)$ was no higher than that normally found in Hungary (about $4 \%$ including congenital cardiovascular malformations). ${ }^{15}$

In summary, approximately $5 \%$ of children of a parent with a congenital cardiovascular malformation will have one too. Genetic counselling should call attention to this enhanced risk and patients should be advised to have their children examined by a cardiologist. As a result of our study four children with congenital cardiovascular malformation were discovered and two have already had an operation.

We thank Professor Attila Árvay and Domokos Boda for access to the data on the index patients.

\section{References}

1 Nora JJ, McGill CW, McNamara DG. Empiric recurrence risks in common and uncommon congenital heart lesions. Teratology 1970; 3: 325-30.

2 Czeizel A, Mészáros M. Two family studies of children with ventricular septal defect. Eur $\mathcal{F}$ Pediatr 1981; 136: 81-5.

3 Czeizel A, Kamarás J, Osztovics M, et al. Genetic family study of congenital cardiovascular malformations in Hungary. (In Hungarian.) Népegészségügy 1974; 55: $153-60$.

4 Nora JJ, Nora AH. The evaluation of specific genetic and environmental counseling in congenital heart diseases. Circulation 1978; 57: 205-13.

5 Neill CA, Swanson S. Outcome of pregnancy in congenital heart disease (abstract). Circulation 1961; 24: 1003-5.

6 Nora JJ, Dodd PF, McNamara DG, Hattwich MAW, Leachman RD, Cooley DA. Risk to offspring of parents

\section{.}


with congenital heart defects. FAMA 1969; 209: 2052-3.

7 Nora JJ, Nora AH. Recurrence risks in children having one parent with a congenital heart disease. Circulation 1976; 53: 701-2.

8 Zetterquist P. A clinical and genetic study of congenital heart defect. The Institute of Medical Genetics, University of Uppsala: MD Thesis, 1972.

9 Ando M, Takao A, Mori K. Genetic and environmental factors in congenital heart disease. In: Inouye $E$, Nishimura H, eds. Gene-environment interaction in common diseases. Baltimore, London, Tokyo: University Park Press, 1977: 71-88.

10 Dennis NR, Warren J. Risks to the offspring of patients with some common congenital heart defects. $\mathcal{F}$ Med Genet 1981; 18: 8-16.

11 Mészáros M, Nagy A, Czeizel A. Incidence of congenital heart disease in Hungary. Hum Hered 1975; 25: 513-9.
12 Mészáros M, Nagy A, Krasznai G, Czeizel A. Birth prevalence of congenital cardiovascular malformations in Hungary. Acta Paediatr Acad Sci Hung 1980; 21: 221-5.

13 McKusick VA. Mendelian inheritance in man. 5th ed. Baltimore \& London: The Johns Hopkins University Press, 1978: 38-9.

14 Carter CO. Genetics of common single malformations. Br Med Bull 1976; 32: 21-6.

15 Czeizel A. The baseline data of the Hungarian Congenital Malformation Register, 1970-1976. Acta Paediatr Acad Sci Hung 1978; 19: 149-56.

Requests for reprints to Dr Andrew Czeizel, Department of Human Genetics, National Institute of Hygiene, Gyáli ut 2-6, 1966 Budapest, Hungary. 